\title{
C1 LATERAL MASS SCREWS FOR POSTERIOR SEGMENTAL STABILIZATION OF THE UPPER CERVICAL SPINE AND A NEW METHOD OF THREE-POINT RIGID FIXATION OF THE C1-C2 COMPLEX
}

\author{
Marcelo D. Vilela ${ }^{1}$, Charles Jermani', Bruno P. Braga ${ }^{1,2}$
}

\begin{abstract}
Objective: To describe our experience with C1 lateral mass screws as part of a construct for C12 stabilization and report an alternate method of C1-C2 complex three-point fixation. Method: All patients that had at least one screw placed in the lateral mass of $C 1$ as part of a construct for stabilization of the C1-C2 complex entered this study. In selected patients who had a higher chance of nonunion an alternate construct was used: transarticular C1-C2 screws combined with C1 lateral mass screws. Results: Twentyone C1 lateral mass screws were placed in 11 patients. In three patients the alternate construct was used. All patients had a demonstrable solid and stable fusion on follow-up. Conclusion: C1 lateral mass screws are safe and provide immediate stability. The use of C1-C2 transarticular screws combined with C1 lateral mass screws is a feasible and also an excellent alternative for a three-point fixation of the C1-C2 complex.

KEY WORDS: C1 lateral mass, C1 lateral mass screws, C1-C2 instability, C1-C2 transarticular screws, atlantoaxial stabilization, cervical spine instrumentation.
\end{abstract}

\begin{abstract}
Parafusos na massa lateral de C1 para instrumentação segmentar da coluna cervical alta e um novo método de fixação em três pontos do complexo C1-C2

RESUMO - Objetivo: Descrever nossa experiência com o uso de parafusos na massa lateral de C1 como parte de uma montagem para estabilização do complexo C1-C2 e relatar uma fixação alternativa em três pontos do complexo C1-C2. Método: Todos os pacientes em que pelo menos um parafuso na massa lateral de C1 foi colocado como parte de uma montagem para estabilização C1-C2 entraram neste estudo. Em certos pacientes com maior chance de não-união, uma montagem alternativa foi usada: parafusos transarticulares C1-C2 associados a parafusos na massa lateral de C1. Resultados: Foram colocados 21 parafusos na massa lateral de C1 em 11 pacientes e em três pacientes foi usada a montagem alternativa. Todos os pacientes evoluíram para uma união sólida e estável. Conclusão: Parafusos na massa lateral de C1 são seguros e conferem estabilidade imediata. Parafusos na massa lateral de C1 combinados a parafusos transarticulares são exequíveis e também excelente alternativa para fixação rígida em três pontos do complexo C1-C2.
\end{abstract}

PALAVRAS-CHAVE: massa lateral de C1, parafusos na massa lateral de C1, instabilidade C1-C2, parafusos transarticulares C1-C2, estabilização atlantoaxial, instrumentação da coluna cervical.

Atlantoaxial instability can be caused by trauma, infection, tumors, arthritis, congenital anomalies, iatrogenic (odontoidectomy) or other less common conditions. Most commonly instability at the C1-C2 complex requires internal fixation not only for immediate stability but also to provide long-term immobility so as to attain a solid fusion. Wiring techniques such as the Gallie, Brooks and modified Brooks are known to provide less than optimal immobilization of the C1-C2 complex not only for axial rotation but also for lateral bending and flexion-extension ${ }^{1,2}$. Newer internal fixation techniques have been developed, which include the transarticular C1-C2 fixation combined with posterior wiring ${ }^{3,4}$, the $\mathrm{C} 1$ lateral mass screw combined with $\mathrm{C} 2$ pedicle screws ${ }^{5}$, the C1-C2 transarticular screws plus a $\mathrm{C} 1$ claw and the $\mathrm{C} 2$ pedicle screws plus a $\mathrm{C} 1$ claw$^{1}$. Biomechanically, a threepoint fixation construct is desirable since it provides superior rigidity ${ }^{1,2}$. In some conditions, such as in smokers, old age, Down's syndrome and rheumatoid dis-

\footnotetext{
${ }^{1}$ Neurosurgeon, Hospital Mater Dei, Belo Horizonte MG, Brazil; ${ }^{2}$ Neurosurgeon, Hospital da Baleia, Belo Horizonte MG, Brazil. Received 31 January 2006, received in final form 8 June 2006. Accepted 27 June 2006.

Dr. Marcelo Duarte Vilela - Department of Neurological Surgery - Box 359766 - Harborview Medical Center, University of Washington - $3259^{\text {th }}$ Avenue - Seattle - WA 98104-2499, USA. E-mail: mdvilela@u.washington.edu
} 
ease, the likelihood of a non-union is high and one must use a construct that is rigid as possible. Furthermore, when there is a fixed C1-C2 subluxation, the space available for the cord is reduced and the passage of sublaminar wires is not always desirable ${ }^{6}$. Still, the use of transarticular screws and a rigid threepoint fixation construct might still be desirable.

In this article, our objective is to show our experience with the use of $\mathrm{C} 1$ lateral mass screws and demonstrate an alternate new three-point fixation technique: the C1 lateral mass screws combined with C1C2 transarticular screws.

\section{METHOD}

Patient population and surgical indications - Eleven patients that underwent a posterior C1-C2 fusion and had at least one $\mathrm{C} 1$ lateral mass screw inserted entered this study (Table). Informed consent was obtained for the publication of the imaging studies in this study. The most common indication for a C1-C2 arthrodesis was traumatic C1C2 instability (8 patients). Two patients had rheumatoid arthritis with $\mathrm{C} 1-\mathrm{C} 2$ subluxation and one patient had Down's syndrome with an os odontoideum and C1-C2 subluxation. There were a total of $21 \mathrm{C} 1$ lateral mass screws placed in eleven patients. One patient had a $\mathrm{C} 1$ lateral mass plus a C2 pedicle screw on one side and a C1-C2 transarticular screw on the other side due to an anomalous vertebral artery course on one side. We used an alternate technique of C1-C2 transarticular screws combined with C1 lateral mass screws in three patients (patients 3,5 and 9). The indications to use this type of construct were the presence of conditions that increase the risk of nonunion combined with a nonreducible $\mathrm{C} 1-\mathrm{C} 2$ subluxation and a reduced space available for the cord. These conditions were Down's syn-

Table. Clinical features and surgery performed.

\begin{tabular}{|c|c|c|}
\hline Patient & $\begin{array}{c}\text { Age } \\
\text { (years) }\end{array}$ & Construct used \\
\hline
\end{tabular}

142 Dove into pool. C1 Jefferson fracture with rupture of the transverse ligament. Neurologically intact.

262 Car accident with C1-C2 distraction injury. Left brachial plexus injury with proximal weakness of the left arm (superior trunk lesion). Morbid obesity.

3

4

5

6

7

8

9

10

11
Old type II dens fracture with nonunion and C1-C2 subluxation. Heavy smoker.

Fall from height with a Jefferson's fracture and rupture of the transverse ligament. Had associated a C7-T1 fracture-dislocation. Mild distal arm weakness bilaterally.

Nonunion of a type II dens fracture with evidence of instability.

Fall from height with Jefferson's fracture and rupture of the transverse ligament. Neurologically intact.

Car accident with type III dens fracture and marked C1-C2 subluxation. Morbid obesity, unsuitable for dens screw or halo bracing. Neurologically intact.

Rheumatoid arthritis with severe neck pain. Neurologically intact. C1-C2 and C3-C4 subluxations.

Down's syndrome with os odontoideum and C1-C2 subluxation. Progressive quadriparesis and dysphagia.

Rheumatoid arthritis with severe neck pain. Mild distal upper extremity weakness bilaterally.

Fall from a height with a Jefferson's fracture and associated T2-T3 flexion-distraction injury.

Neurologically intact.
C1 lateral mass screws plus C2 pedicle screws.

C1 lateral mass screws plus C2 pedicle screws.

C1-C2 transarticular screws and C1 lateral mass screws (Fig 2A).

C1 lateral mass screws plus C2 pedicle screws and C6-T2 circumferential fusion.

C1-C2 transarticular screws and C1 lateral mass screws.

C1-C1 plate using C1 lateral mass screws plus C1-C2 transarticular screws.

C1 lateral mass screws plus C2 pedicle screws (Fig 2B).

C1 lateral mass screws plus $C 2$ pedicle screws on right side, C1-C2 transarticular screws on the left side plus C3-C4 lateral mass screws (C1-C4 fusion) (Fig 2C)

C1-C2 transarticular screws and C1 lateral mass screws (Fig 3A).

Occipital - C4 fusion using C1 lateral mass screws, C2 pedicle screws and C3-C4 lateral mass screws (Fig 3B).

C1 lateral mass screws plus C2 pedicle screws and T1-T4 posterior fusion. 
drome with an os odontoideum in one patient, and two cases of post-traumatic C1-C2 subluxations with non-union of a type II dens fracture, one patient being a heavy smoker and the other an 85 year-old patient, who would refuse to wear a collar postoperatively. Additionally, we wanted to avoid postoperative halo bracing in these fragile patients.

There were no complications related to the insertion of the screws nor there was a need to reposition any screw. All patients had postoperative computed tomographic scans confirming adequate positioning of all screws. All C1 screws were satisfactorily placed in the lateral mass without violation of neither the lateral nor medial cortex and/or vertebral artery foramen.

All patients were followed monthly for the first three months, with a documentation of the neurological exam and upright $\mathrm{X}$-rays of the cervical spine. All patients were instructed to wear a collar postoperatively for at least three months. Flexion-extension films were obtained at least 12 weeks postoperatively to document stability and evidence of fusion. Follow-up ranged from 6 to 24 months.

Surgical technique - Cervical spine fine-cut CT scans were carefully studied preoperatively to ensure safe placement of transarticular screws and C2 pedicle screws. In only one patient the placement of transarticular screws was considered dangerous, on one side only. All patients were positioned in the ventral position with the head fixed in a threepoint head holder. After dissection of the paraspinal muscles from the occipital squamae and C1-C2 posterior elements, the $\mathrm{C} 1$ posterior arch was exposed bilaterally to the point of the transverse foramen of the atlas, taking care not to injure the vertebral artery. The vertebral artery was then carefully identified coursing along its groove, usually at 8-12 $\mathrm{mm}$ from the midline on the superior aspect of

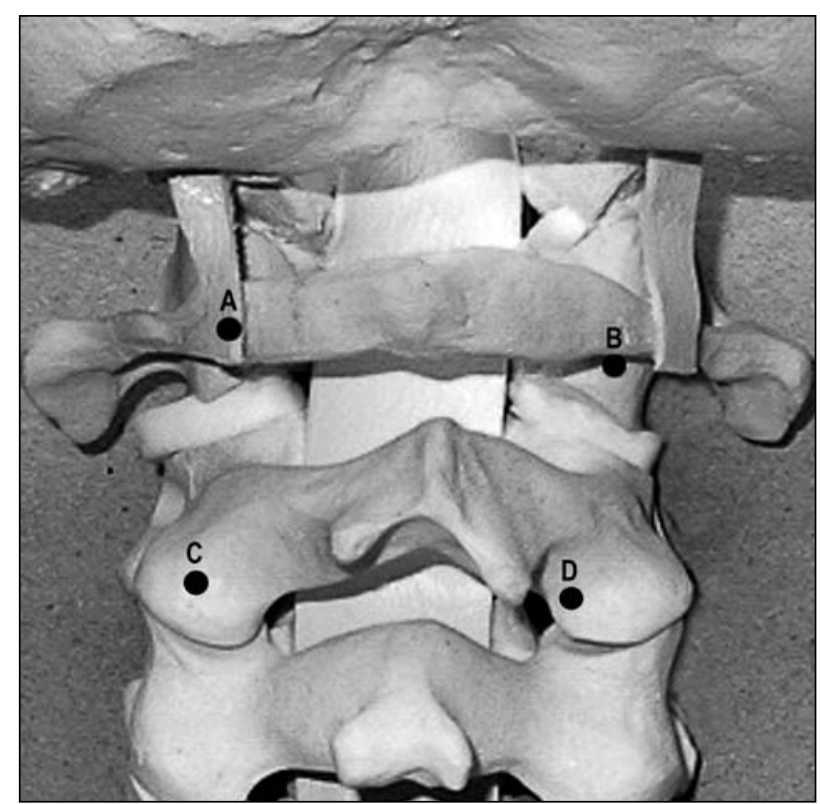

Fig 1. Photograph of a spine model showing the entry points for the placement of $C 1$ lateral mass screws $(A, B), C 2$ pedicle screws (C) and C1-C2 transarticular screws (D).

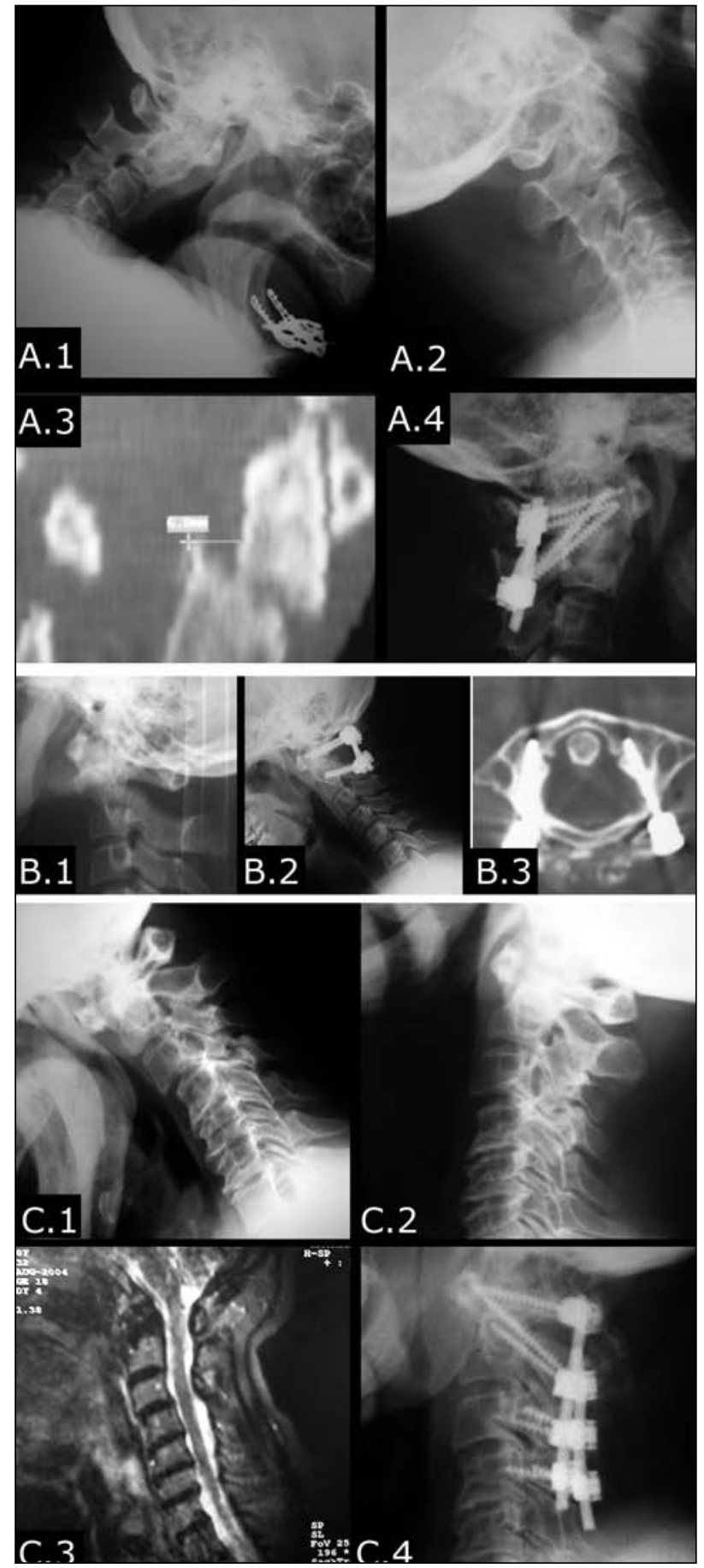

Fig 2. A.1 and A.2: Flexion-extension views demonstrating a fixed C1-C2 subluxation due to a dens type II fracture; A.3: sagittal reconstruction CT scan showing an old dens fracture and C1-C2 subluxation; A.4: Postoperative lateral C-spine view shows a three-point C1-C2 fixation using C1-C2 transarticular screws plus C1 lateral mass screws. B.1:C-spine lateral $x$-ray showing a dens fracture with marked anterior C1-C2 subluxation; B.2: 12-week postoperative C-spine flexion $x$-ray showing a solid fusion after $C 1$ lateral mass screws combined with C2 pedicle screws fixation; B.3: CT scan demonstrating optimal placement of the $\mathrm{C} 1$ lateral mass screws. C. 1 and C.2: C-spine flexion-extension $x$-rays showing C1-C2 and C3-C4 subluxations; C.3: MRI scan showing erosion of the dens, C1-C2 and C3-C3 subluxations; C.4: Postoperative C-spine lateral $x$-ray showing a segmental C1-C4 posterior fixation. 


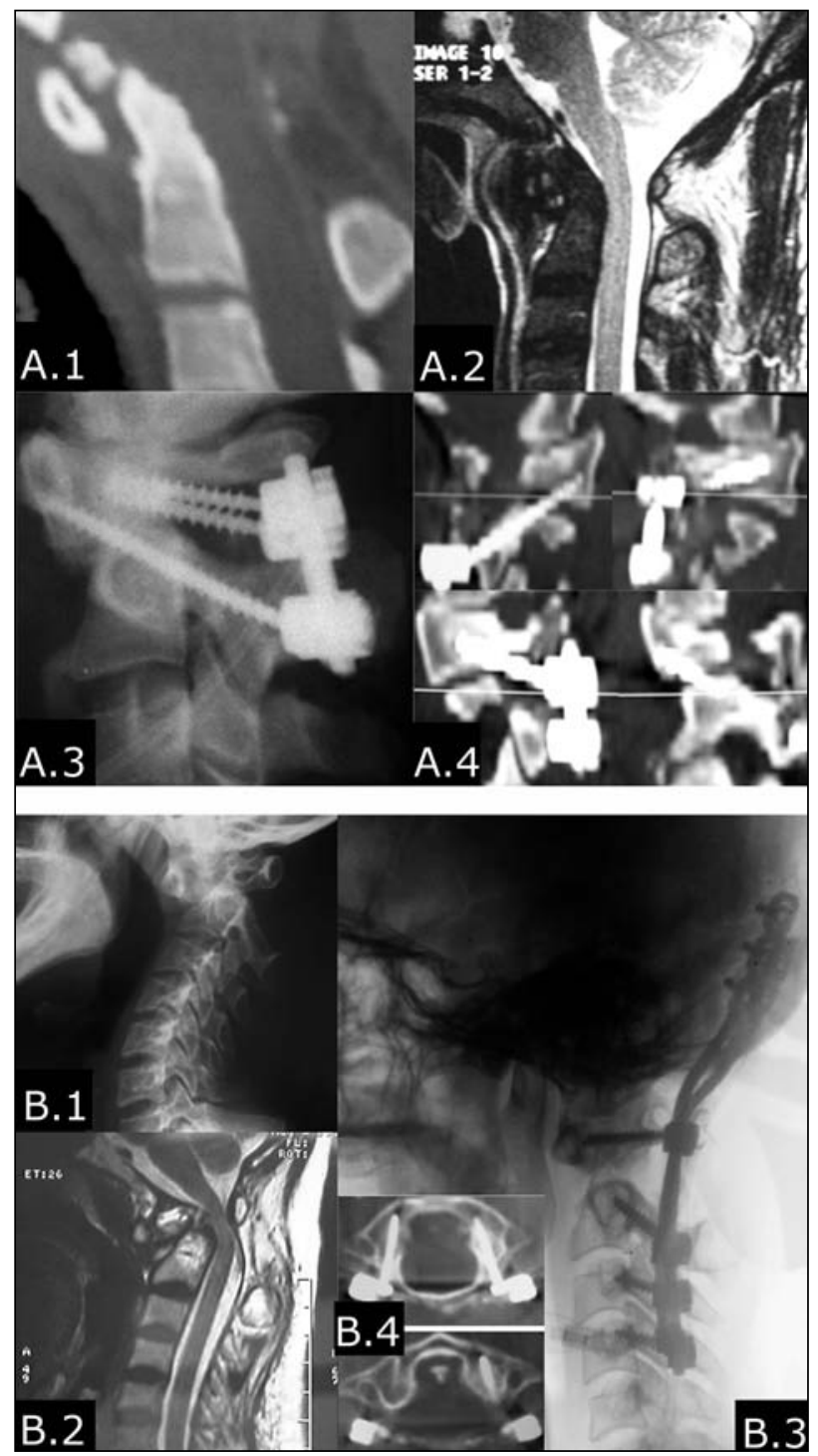

Fig 3. A.1 and A.2: C-spine sagital reformatted CT scan and MRI scan showing an os odontoideum associated with C1-C2 subluxation and spinal cord compression; A.3: Postoperative C-spine lateral $X$-ray showing a three-point construct with C1-C2 transarticular screws plus $\mathrm{C1}$ lateral mass screws; A.4: Postoperative CT scan showing C1-C2 transarticular screws plus C1 lateral mass screws. B.1: Lateral C-spine $x$-ray demonstrating a severe C1-C2 subluxation with marked erosion of the dens and increased atlanto-dens interval. B.2: T2-weighed MRI scan showing dens erosion, markedly increased atlanto-dens interval and spinal cord compression; B.3: Postoperative lateral C-spine $x$-ray showing segmental occipital-C4 fixation. B.4: CT scan showing optimal placement of C1 lateral mass screws and restoration of a normal atlanto-dens interval.

the atlas ${ }^{7}$, and dissected off the bone. There was no need to dissect the artery from the surrounding veins. The medial surface of the $\mathrm{C} 1$ lateral mass and the $\mathrm{C} 1$ foramen transversarium were identified using a $\mathrm{n}^{\circ} 4$ Penfield dissector, providing the proper anatomical orientation for the screw entry point and trajectory. Any venous bleeding was easily stopped using hemostatic agents and gentle packing. We avoid coagulating close to the vertebral artery since it obscures the anatomy and does not efficiently stops oozing.

An entry point directly on the posterior arch of the atlas, midpoint between the medial edge of the foramen transversarium and the medial surface of the lateral mass is then chosen (Fig 1A). In some patients a starting point on the lateral mass just below the $\mathrm{C} 1$ posterior arch was chosen because of a too thin posterior arch (Fig 1B). A starting point using a $3 \mathrm{~mm}$ burr was then made on the posterior arch, while the assistant protected the vertebral artery with a Penfield dissector. The lateral mass was then perforated using a hand-held drill with a $2.5 \mathrm{~mm} \mathrm{~K}$-wire, under fluoroscopy, stopping just short to the anterior arch cortex, with the drill bit angled medially 5-10 degrees. After drilling the pilot hole and feeling the trajectory with a blunt $1.0 \mathrm{~mm}$ probe, the hole was tapped and a $3.5 \mathrm{~mm}$ screw inserted. Usually the screw measures $18-30 \mathrm{~mm}$ in length, depending on the size of the lateral mass and whether the starting point is on or below the posterior arch.

Placement of either C2 pedicle screws (Fig 1C) or C1-C2 transarticular screws (Fig 1D) is then performed, depending on the construct planned. The screws are then connected to rods and any additional correction achieved. A crosslink between the $\mathrm{C} 1$ and $\mathrm{C} 2$ connectors can be used to increase rigidity in the rotational and axial planes. An iliac crest autograft is then laid between the decorticated C1C2 posterior elements and intraarticular surfaces (Figs 2 and 3).

\section{RESULTS}

All patients had immediate stability provided by the construct, verified intraoperatively and subsequently demonstrated on upright imaging studies. A cervical rigid collar was recommended postoperatively for at least three months in all patients. A halovest was not judged necessary in any patient. Two patients refused to wear a collar: patient 2 , due to morbid obesity and patient 5, who was unable to walk with a collar on.

There was no loss of reduction or hardware failure during follow-up. There were no complications related to the placement of the screws per se. There was no worsening of the neurological status after surgery in any patient but in patient 5 , who had mild dysphagia and required a feeding tube for three weeks postoperatively. Two patients had a superficial wound infection: patient 10 , who was on longterm steroids and patient 2, who had morbid obesity. Both recovered well with antibiotics and minor debridement. Patient 9 expired eight months after surgery due to gastrointestinal complications related to his 21 trisomy.

\section{DISCUSSION}

C1-C2 stabilization and fusion when relied on wiring techniques, such as the Gallie, Brooks and 
modified Brooks quite often did not provide sufficient rigidity and as a result nonunions rates were high $^{6,8-10}$. More recently, studies on biomechanics of the atlantoaxial joint have demonstrated that its kinematics is indeed complex and there is intervertebral coupled motion at the C1-C2 joints ${ }^{11}$. For instance, when there is right rotation of the atlas, there are coupled left lateral bending and extension of the lateral masses ${ }^{11}$. The greatest degree of motion at the atlantoaxial joints takes place with axial rotation, which has about 36-41.5 degrees of movement to each side ${ }^{11}$. Although wiring techniques restrict flexion-extension, they allow considerable motion during axial rotation and bending ${ }^{1,12}$. In 1987, Magerl introduced the technique of C1-C2 transarticular screws combined with a posterior wiring technique, which provided a three-point fixation of the C1-C2 complex ${ }^{3}$. This technique was later shown biomechanically to prevent motion in all planes very efficiently $1,2,12-14$. Various authors subsequently demonstrated the superiority of transarticular screws combined with posterior wiring when compared to posterior wiring alone in the treatment of C1-C2 instability 4,6,9,10,15-17.

There are some drawbacks in the use of C1-C2 transarticular screws, though. The C1-C2 alignment has to be perfect prior to inserting the screws, there is the risk of injuring the vertebral artery, especially when it is high-riding or has an anomalous course, and the proper angle of the screws can not be achieved when the patient has a marked thoracic kyphosis or is markedly obese. Harms subsequently described the technique of $\mathrm{C} 1$ lateral mass screws combined with $\mathrm{C} 2$ pedicle screws as a way to immobilize the C1-C2 complex ${ }^{5}$. The efficacy of this technique in achieving high fusion rates and good outcomes was clearly demonstrated ${ }^{5}$.The main advantages are that it can be used in patients with a rigid neck, in those patients who have an anomalous course of the vertebral artery or when the vertebral artery is high-riding. Furthermore, the $\mathrm{C} 1$ and $\mathrm{C} 2$ screws can be placed before reduction is performed.

The technique of $\mathrm{C} 1$ lateral mass combined with $\mathrm{C} 2$ pedicle screws provides at least the same rigidity as the C1-C2 transarticular screws combined with posterior wiring and superior stability when compared to wiring techniques alone ${ }^{1,12,13}$. Different biomechanical studies have demonstrated that this type of construct provides not only immediate stability but and also rigidity in flexion-extension, lateral bending and axial rotation ${ }^{1,12,13}$.

The use of $\mathrm{C} 1$ lateral mass screws can also be particularly useful when a multilevel segmented instru- mentation is needed. Two of our patients had a multilevel fusion in which C1 screws were placed as part of the construct. Both patients had rheumatoid arthritis. In patient 10, this was particularly useful: the placement of the $\mathrm{C} 1$ and $\mathrm{C} 2$ screws was done after a few occipital screws and the rods were in place, which helped achieving the final reduction by pulling C1 backwards and pushing C2 anteriorly.

The suitability of the lateral mass to accept screws has been demonstrated either via posterior arch or lateral mass alone ${ }^{18-20}$. Moreover, the pullout strength of the $\mathrm{C} 1$ lateral mass screws has been shown to be equivalent to the $\mathrm{C} 2$ pedicle screws ${ }^{18}$. We prefer placing $\mathrm{C} 1$ lateral mass screws with a starting point right on the posterior arch of the atlas, as suggested by Tan et al. ${ }^{20}$. We point some advantages that led this technique to be our preferred method.

The posterior arch has considerable thickness to

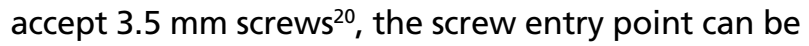
easily chosen ${ }^{20}$ with minimal additional dissection, there is no need to sever or manipulate the $\mathrm{C} 2$ root, the screws trajectory is longer and the $\mathrm{C} 1$ screw head can be perfectly aligned with the $\mathrm{C} 2$ screw head. Our preferred entry point is usually midway between the foramen transversarium and the posterior medial edge of the $\mathrm{C} 1$ lateral mass.

We usually aim the anterior arch and angle the K- wire 5-10 degrees medially, using continuous fluoroscopy. With this technique, there were no instances of vertebral, dural or nerve root injury. In two patients we were not able to place screws directly on the posterior arch due to its small size and an entry point below the arch was used.

Although choosing $\mathrm{C} 1$ lateral mass screws combined with $\mathrm{C} 2$ pedicle screws can be a good alternative when transarticular screws are not feasible, the placement of $\mathrm{C} 2$ pedicle screws can also injure the vertebral artery, especially when it has a more medial course ${ }^{19}$. When this is the case, we prefer placing a shorter screw (pars screw) that stops just posterior to the vertebral artery foramen.

The idea of building a construct that uses a threepoint fixation comes from the principles of biomechanics that the more points of fixation one uses, the more rigid and stable the construct is ${ }^{2}$. Several techniques using a three-point construct for stabilizing the C1-C2 complex have been described and also tested biomechanically. They include the C1-C2 transarticular screws combined with posterior wiring, the C1-C2 transarticular screws combined with a C1 claw and the $\mathrm{C} 2$ pedicle screws combined with a $\mathrm{C} 1 \mathrm{claw}^{1}$. 
These techniques have also been studied biomechanically and the C1-C2 transarticular screws combined with posterior wiring and the C1-C2 transarticular screws combined with a $\mathrm{C} 1$ claw showed the smallest overall range of motion and neutral zone ${ }^{1}$. The C2 screws plus a C1 claw construct had larger values of range of motion and neutral zone for axial rotation, flexion-extension and lateral bending ${ }^{1}$.

Our idea of building a construct using $\mathrm{C} 1-\mathrm{C} 2$ transarticular screws and $\mathrm{C} 1$ lateral mass screws also comes from these principles of a three-point fixation system. The particular anatomy of the C1 lateral mass, with its unique configuration (high and wide), allows placement of two independent screws on the same lateral mass, as we have done in some patients. The transarticular screw purchases the lateral mass at its anterior-inferior portion while the $\mathrm{C} 1$ screw purchases the middle portion of the lateral mass. The rods connecting the two screws establish a posterior tension band and the addition of a cross-link adds significant rotational and axial stability. Although we have not done any biomechanical study, we can infer that this type of construct provides at least the same stability provided by the $\mathrm{C} 1$ lateral mass screws combined with $\mathrm{C} 2$ pedicle screws and at least the same stability conferred by $\mathrm{C} 1-\mathrm{C} 2$ transarticular screws alone.

Although some may argue that the transarticular screws combined with a wiring technique provide an excellent three-point fixation technique ${ }^{1,2,12,14}$, the passage of sublaminar wires is not without haz$\operatorname{ards}^{10,17}$. This might be especially true for those patients in which there is a non-reducible C1-C2 subluxation and/or reduced space available for the cord. Several authors have described worsening of a preexisting myelopathy as a complication of passing sublaminar wires, particularly in patients with rheumatoid arthritis and/or os odontoideum ${ }^{6,10}$. For that reason, they recommended transarticular screws when stabilizing the C1-C2 complex in the presence of an os odontoideum, avoiding posterior wiring ${ }^{6}$.

We used this new technique of C1-C2 transarticular screws combined with $\mathrm{C} 1$ lateral mass screws in three patients. The indications to use this type of construct were the combinations of conditions that increase the risk of nonunion combined with a nonreducible $\mathrm{C} 1-\mathrm{C} 2$ subluxation and a small space available for the cord. Additionally, it was desirable to build a construct as rigid as possible so as to avoid postoperative halo bracing in these fragile patients.

In conclusion, C1 lateral mass screws are a safe method of obtaining segmental fixation of the atlas. They can be especially valuable when a multilevel segmental construct that includes the occipitocervical junction or subaxial cervical spine is desired. The use of C1-C2 transarticular screws combined with C1 lateral mass screws proved to be a feasible and efficacious method of three-point fixation of the C1-C2 complex. It can be particularly useful in those cases when the $\mathrm{C} 1$ posterior arch is fractured, when a C1 laminectomy is required, or when the surgeon wishes to place transarticular screws and do a three-point fixation but avoid the risks of passing sublaminar wires.

\section{REFERENCES}

1. Richter M, Schmidt R, Claes L, Puhl W, Wilke HJ. Posterior atlantoaxial fixation: biomechanical in vitro comparison of six different techniques. Spine 2002;27:1724-1732.

2. Naderi ST, Crawford, NR, Song, GS; Sonntag, VK, Dickman, CA. Biomechanical comparison of C1-C2 posterior fixations: cable, graft, and screw combinations. Spine 1998;23:1946-1955.

3. Magerl F, Seeman P. Stable posterior fusion of the atlas and axis by transarticular screw fixation. In Kehr P, Weidner A (eds). Cervical spine. Strassbourg, Wien, New York: Springer-Verlag, 1985:322-327.

4. Dickman CA, Sonntag VK. Surgical management of atlantoaxial nonunions. J Neurosurg 1995;83:248-253.

5. Harms J, Melcher RP. Posterior C1-C2 fusion with polyaxial screw and rod fixation. Spine 2001;26:2467-2471

6. Coyne TJ, Fehlings MG, Wallace MC, Bernstein M, Tator CH. C1-C2 Posterior cervical fusion: long-term evaluation of results and efficacy. Neurosurgery 1995;37:688-693.

7. Ebraheim NA, Xu R, Ahmad M, Heck B. The quantitative anatomy of the vertebral artery groove of the atlas. Spine 1998;23:320-323.

8. Dickman CA, Crawford NR, Paramore CG. Biomechanical characteristics of C1-2 cable fixations. J Neurosurg 1996;85:316-322.

9. Taggard DA, Kraut MA, Clark CR, Traynelis VC. Case-control study comparing the efficacy of surgical techniques for C1-C2 arthrodesis. J Spinal Disord Tech 2004;17:189-194.

10. Reilly TM, Sasso RC, Hall PV. Atlantoaxial stabilization: clinical comparison of posterior cervical wiring technique with transarticular screw fixation. J Spinal Disord Tech 2003;16:248-253.

11. Ishii T, Mukai $Y$, Hosono N, et al. Kinematics of the subaxial cervical spine in rotation in vivo three-dimensional analysis. Spine 2004;29:28262831.

12. Melcher RP, Puttlitz CM, Kleinstueck FS, Lotz JC, Harms J, Bradford DS. Biomechanical testing of posterior atlantoaxial fixation techniques. Spine 2002;27:2435-2440.

13. Kim SM, Lim TJ, Paterno J, et al. Biomechanical comparison of anterior and posterior stabilization methods in atlantoaxial instability. J Neurosurg 2004;100:277-283.

14. Mitchell, TC, Sadasivan KK, Ogden AL, et al. Biomechanical study of atlantoaxial arthrodesis: transarticular screw fixation versus modified brooks posterior wiring. J Orthop Trauma 1999;13:483-489.

15. Haid RW Jr, Subach BR, McLaughlin MR, Rodts GE Jr, Wahlig JB Jr. C1C2 transarticular screw fixation for atlantoaxial instability: a 6-year experience. Neurosurgery 2001;49:65-68.

16. Dickman CA, Sonntag VK. Posterior C1-C2 transarticular screw fixation for atlantoaxial arthrodesis. Neurosurgery 1998;43:275-280.

17. Eleraky MA, Masferrer R, Sonntag VK. Posterior atlantoaxial facet screw fixation in rheumatoid arthritis. J Neurosurg 1998; 89:8-12.

18. Hong X, Dong Y, Yunbing C, Qingshui Y, Shizheng Z, Jingfa L. Posterior screw placement on the lateral mass of atlas: an anatomic study. Spine 2004;29:500-503.

19. Resnick DK, Lapsiwala S, Trost GR. Anatomic suitability of the C1-C2 complex for pedicle screw fixation. Spine 2002; 27:1494-1498.

20. Tan $M$, Wang $H$, Wang $Y$, et al. Morphometric evaluation of screw fixation in atlas via posterior arch and lateral mass. Spine 2003;28:888-895. 